\title{
Serum Hepcidin Quantification in Stroke in $\beta$-Thalassemia and Rheumatoid Arthritis Patients
}

\author{
Manolov V ${ }^{*}$, Petrova J ${ }^{2}$, Hadjidekova $\mathrm{S}^{3}$, Petrova \\ $M^{2}$, Traykov $L^{2}$, Tarnovska-Kadreva $R^{4}$, Yaneva- \\ Sirakova $T^{4}$, Vasilev $V^{1}$, Tzatchev $K^{1}$, Marinov $\mathbf{B}^{5}$, \\ Paskaleva-Peycheva $V^{6}$, Emilova $R^{7}, \operatorname{Bogov} I^{8}$, \\ Gramatikova $Z^{\mathbf{9}}$ and Dimitrov $\mathbf{G}^{\mathbf{4}}$ \\ ${ }^{1}$ Department of Clinical Laboratory and Clinical \\ Immunology, Medical University, Bulgaria \\ ${ }^{2}$ Department of Neurology, Medical University, Bulgaria \\ ${ }^{3}$ Department of Medical Genetics, Medical University, \\ Bulgaria \\ ${ }^{4}$ Department of Cardiology, Medical University, Bulgaria \\ ${ }^{5}$ Maichin Dom University Hospital, Bulgaria \\ ${ }^{6}$ Department of Internal Diseases, Medical University, \\ Bulgaria \\ ${ }^{7}$ Specialized Hospital for Active Treatment in Pediatrics, \\ Bulgaria \\ ${ }^{8}$ National Cardiological Hospital, Bulgaria \\ ${ }^{9}$ R.E.D. Laboratories NV/SA, Belgium \\ *Corresponding author: Victor Manolov, Department \\ of Clinical Laboratory and Clinical Immunology, Medical \\ University, 1 Georgi Sofiiski bul, 1431 Sofia, Bulgaria
}

Received: October 27, 2016; Accepted: March 16, 2017; Published: March 31, 2017

\begin{abstract}
Background and Purpose: Anemia occurs often in different conditions, associated with iron metabolism and flowing in a number of diseases. Variations in serum levels of iron is due to a number of reasons, such as bleeding from the gastrointestinal tract, inflammation, production of inflammatory cytokines, deposition of iron in various tissue structures, and etc. Oxidative stress plays an important role in neuronal injuries caused by cerebral ischemia. We aimed to quantify serum hepcidin in rheumatoid arthritis patients with ischemic stroke and $\beta$-thalassemia with stroke and evaluate peptide changes in combination of two diseases.
\end{abstract}

Methods: For a period of two years 138 patients with ischemic stroke were enrolled. They were separated into three groups - 49 with ischemic stroke, caused by vascular reasons (ISVR), 43 patients with rheumatoid arthritis (RA) and $46 \beta$-thalassemia cases (BTM). Their results were compared to age and gender matched healthy controls. Established parameters from rheumatoid arthritis and $\beta$-thalassemia cases were compared with RA and BTM patients without stroke. Statistical analysis of established results was performed using Pearson's correlation and Student's paired t-test.

Results: We found statistically different results from included groups for serum hepcidin levels. They differ in case if an acute stroke occurs during rheumatoid arthritis or $\beta$-thalassemia. Serum hepcidin levels statistically differ in three ischemic stoke groups: ISVR $87.6 \pm 9.4 \mu \mathrm{g} / \mathrm{L}$, RA $19.4 \pm 0.9 \mu \mathrm{g} / \mathrm{L}$ and BTM $7.9 \pm 1.1 \mu \mathrm{g} / \mathrm{L}(P<0.001)$. In patients with RA and BTM without stroke hepcidin shows serum concentrations from $35.6 \pm 1.4 \mu \mathrm{g} / \mathrm{L}$ and $0.95 \pm 0.3 \mu \mathrm{g} / \mathrm{L}(P<0.001)$. In healthy controls we quantified serum hepcidin as $22.7 \pm 5.1 \mu \mathrm{g} / \mathrm{L}$.

Conclusion: Our study in patients with acute stroke, rheumatoid arthritis and stroke and $\beta$-thalassemia and stroke confirms the ability of verified immunochemical method for evaluation of iron homeostasis. It provides a basis for the correct choice of therapeutic approach in anemia treatment. Rheumatoid arthritis increases serum hepcidin levels in stroke; in patients with $\beta$-thalassemia peptide's concentration decreases. Dissimilar diseases are accompanied with iron disorders, thereby masking the state of this trace element in human body.

Keywords: Stroke; Anemia; Rheumatoid arthritis; Hepcidin; Iron deficiency; Anemia in chronic inflammation; Thalassemia

\section{Introduction}

Anemia in rheumatoid arthritis is a process associated with chronic inflammatory disease. It occurs as iron deficiency, mostly due to drug-induced gastrointestinal bleeding and disorders as well as iron redistribution into inflamed joint structure. Identifying and finding the right treatment approach for iron deficiency in patients with anemia of chronic disease is of great clinical importance because it can prevent unnecessary spelling of therapy with iron preparations.

Proinflammatory stimuli leads to the development of anemia of chronic disease by directly inhibit erythropoiesis indirectly reduce iron supplied for the synthesis of heme [1]. This process is associated with increased levels of regulatory peptide hepcidin due to inflammation. Elevated hepcidin decreased intestinal iron absorption. Due to the occurrence of changes in the molecule of the cell iron exporter - ferroportin (by which hepcidin acts on iron homeostasis), occurs iron retention in macrophages and iron sequestration in the reticuloendothelial system $[2,3]$. Consequently, the total content of iron in the body is normal, but less is supplied for erythropoiesis. Opposite is the mechanism for the development of iron deficiency anemia. When it is observed absolute iron deficiency, hepcidin secretion is suppressed, leading to stimulation of the absorption of iron in the intestine.

Hepcidin, an iron metabolism regulatory peptide has been proposed as a risk factor for atherosclerosis [4], and there is recent evidence supporting this possibility [5]. Low hepcidin production combined with increased ferroportin synthesis strongly favors release of iron from reticuloendothelial storage sites and thus supports a shift of endogenous iron from storage to new red blood cell hemoglobin. Oxidative stress plays an important role in neuronal injuries caused
Austin J Cerebrovasc Dis \& Stroke - Volume 4 Issue 2 - 2017 ISSN : 2381-9103 | www.austinpublishinggroup.com Manolov et al. () All rights are reserved
Citation: Manolov V, Petrova J, Hadjidekova S, Petrova M, Traykov L, Tarnovska-Kadreva R, et al. Serum Hepcidin Quantification in Stroke in $\beta$-Thalassemia and Rheumatoid Arthritis Patients. Austin J Cerebrovasc Dis \& Stroke. 2017; 4(2): 1056. 
Table 1: Age distribution of patients in included groups.

\begin{tabular}{|c|c|c|}
\hline Group & M:F & Age \\
\hline ISVR & $27(55.1 \%): 22(44.9 \%)$ & $50.4 \pm 7.2$ \\
\hline RA and Stroke & $2(16.7 \%): 10(83.3 \%)$ & $53.7 \pm 9.1$ \\
\hline RA no Stroke & $5(16.1 \%): 26(83.9 \%)$ & $51.6 \pm 6.9$ \\
\hline BTM and Stroke & $3(60 \%): 2(40 \%)$ & $42.3 \pm 1.2$ \\
\hline BTM no Stroke & $18(43.9 \%): 23(56.1 \%)$ & $25.1 \pm 5.4$ \\
\hline Control group & $26(51 \%): 25(49 \%)$ & $39.4 \pm 5.7$ \\
\hline
\end{tabular}

*ISVR: Ischemic Stroke Vascular Reason; RA: Rheumatoid Arthritis; BTM: $\beta$-Thalassemia

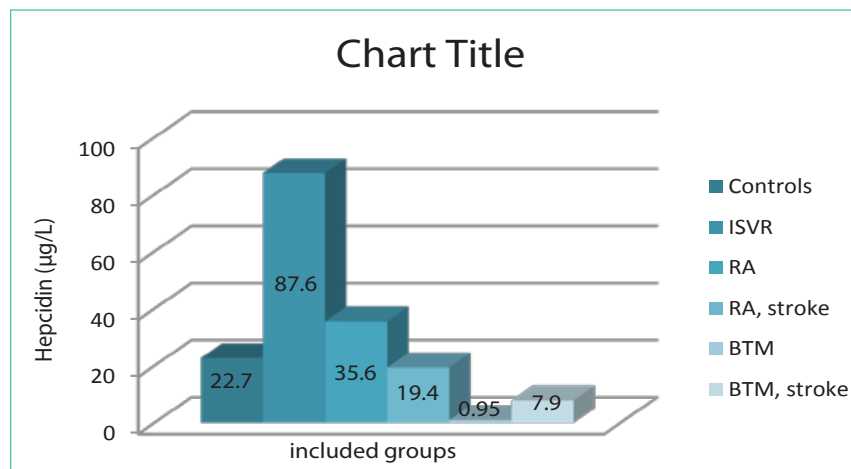

Figure 1: Serum hepcidin concentrations (in $\mu \mathrm{g} / \mathrm{L}$ ) in the different groups of patients included in this study.

*ISVR: Ischemic Stroke, Vascular Reason; RA: Rheumatoid Arthritis; BTM: $\beta$-Thalassemia.

by cerebral ischemia. It is known that free iron increases significantly during ischemia and is responsible for oxidative damage in the brain. Many mechanisms are involved in ischemia-induced brain injuries, such as oxidative stress [6], increased intracellular calcium concentration [7], inflammation [8], and elevated excitatory amino acids [9]. Increased levels of free iron and ferritin have been observed in ischemic brain [10]. Elevated hypoxia inducible factor 1 (HIF-1) expression causes high secretion of hepcidin [11].

\section{Methods}

For a period of two years 138 patients with ischemic stroke were enrolled. They were separated into three groups - 49 with ischemic stroke, caused by vascular reasons (ISVR), 43 patients with rheumatoid arthritis (RA) and $46 \beta$-thalassemia cases (BTM). Including criteria for ischemic stroke were vascular changes, monitored by ultrasound investigation, and never had history of TIA, stroke and MI. Their results were compared to age and gender matched healthy controls, which results were obtained from previous studies, during evaluation of hepcidin reference ranges in Bulgarian population. Established parameters from rheumatoid arthritis and $\beta$-thalassemia cases were compared with RA and BTM patients without stroke. RA patients were diagnosed in Department of Rheumatology at "St. Ivan Rilski" hospital. Disease activity was determined by Disease Activity Score calculator for rheumatoid arthritis [DAS 28-CRP]. Patients with rheumatoid arthritis were with anemia in chronic diseases (ACD). $\beta$-thalassemia patients were monitored in Intensive Cardiology Dept. at University "Aleksandrovska" hospital. All acute stroke cases, including RA patients were diagnosed in Neurology Dept. at the same hospital.
Table 2: Established parameters from $\mathrm{CBC}$ and laboratory assessment of included groups (presented as mean \pm SD).

\begin{tabular}{|c|c|c|c|c|c|c|c|c|}
\hline \multirow{2}{*}{ Parameter } & \multicolumn{2}{|c|}{ ISVR } & \multicolumn{2}{|c|}{ BTM } & \multicolumn{2}{|c|}{ RA } & \multicolumn{2}{|c|}{$\begin{array}{c}\text { Control } \\
\text { group }\end{array}$} \\
\hline & mean & SD & mean & SD & mean & SD & mean & SD \\
\hline CRP mg/L & 5.41 & 1.1 & 4.78 & 0.9 & $22.5^{*}$ & 2.2 & $1.62^{*}$ & 0.9 \\
\hline $\mathrm{Hb} \mathrm{g} / \mathrm{L}$ & $119.4^{*}$ & 19.8 & $100.4^{*}$ & 14.8 & $124.1^{*}$ & 15.1 & $142.6^{*}$ & 18.8 \\
\hline $\mathrm{RBC}{ }^{*} 10^{12} / \mathrm{L}$ & 4.19 & 1.6 & $3.74^{*}$ & 1.5 & 4.45 & 2.1 & $4.98^{*}$ & 1.5 \\
\hline $\mathrm{CHr} p g$ & $24.7^{\star}$ & 1.7 & $22.9^{*}$ & 1.6 & 29.7 & 2.1 & $32.3^{*}$ & 2.8 \\
\hline $\begin{array}{c}\text { Creatinine } \\
\mu \mathrm{mol} / \mathrm{L}\end{array}$ & 71.8 & 2.9 & 57.5 & 2.5 & 64.9 & 3.1 & 73.1 & 3.9 \\
\hline Iron $\mu \mathrm{mol} / \mathrm{L}$ & $45.6^{*}$ & 2.5 & $55.8^{*}$ & 3.1 & $12.6^{*}$ & 1.5 & $18.71^{*}$ & 1.8 \\
\hline $\mathrm{TIBC} \mu \mathrm{mol} / \mathrm{L}$ & $69.9^{*}$ & 2.8 & $97.75^{*}$ & 4.1 & 63.2 & 2.4 & 64.5 & 2.9 \\
\hline $\mathrm{Fe} / \mathrm{TIBC}$ & 0.65 & - & 0.57 & - & 0.199 & - & 0.29 & - \\
\hline sol. TRF mg/L & 2.78 & 0.8 & $3.19^{*}$ & 1.2 & $1.26^{*}$ & 0.4 & 2.97 & 0.4 \\
\hline Ferritin ng/mL & $194.5^{*}$ & 21.7 & $901.22^{*}$ & 35.6 & 154.5 & 3.4 & $89.2^{*}$ & 4.7 \\
\hline Glucose $\mathrm{mmol} / \mathrm{L}$ & 4.91 & 0.7 & 4.9 & 1.4 & 4.79 & 1.2 & 4.81 & 1.0 \\
\hline TRSF g/L & 2.58 & 0.3 & 2.18 & 0.4 & 2.64 & 0.4 & 2.96 & 0.5 \\
\hline ASAT U/L & 29.7 & 1.1 & 21.3 & 1.1 & 24.9 & 1.2 & 21.6 & 1.2 \\
\hline ALAT U/L & 26.5 & 0.9 & 18.1 & 1.3 & 21.8 & 1.8 & 19.2 & 1.9 \\
\hline $\mathrm{IL}-6 \mathrm{pg} / \mathrm{mL}$ & \multicolumn{2}{|c|}{ n.a. } & \multicolumn{2}{|c|}{ n.a. } & 3.6 & 0.4 & 1.4 & 0.2 \\
\hline
\end{tabular}

${ }^{*}$ CRP: C-Reactive Protein; CBC: Complete Blood Count; Hb: Hemoglobin; RBC: Red Blood Cells; CHr: Concentration of Hemoglobin in Reticulocytes; TIBC: Total Iron Bonding Capacity; TRF: Soluble Transferrin Receptors; TRSF: Transferrin; ASAT: Aspartate Amino-Transferase; ALAT: Alanine Amino-Transferase; IL-6: Interleukin-6; statistical significance $P<0.05$.

We quantify serum hepcidin levels using verified ELISA method [12] from previous studies. Atomic Absorption Spectrometry (AAS) was used for quantification of serum iron and total iron binding capacity (TIBC). Serum ferritin levels were quantified by CLIA method (Immulyte 2000, by Siemens Healthcare). Soluble transferrin receptors and CRP were measured by nephelometric method (Siemens Healthcare). CBC, including hemoglobin concentration in reticulocytes (CHr) was quantified on ADVIA 2120 (provided by Siemens Healthcare). All chemical laboratory parameters were specified on Dimension RxL MAX (Siemens Healthcare Diagnostics).

Unpaired t-test and Pearson's correlation were used for statistical analysis.

Enrolled patients signed written informed consent according to the Declaration of Helsinki (Directive 2001/20 / EC).

\section{Results}

Age distribution of patients in the different included groups is shown in Table 1.

Established parameters from $\mathrm{CBC}$ and laboratory assessment are presented in Table 2.

RA patients showed elevated CRP levels $22.5 \mathrm{mg} / \mathrm{L}$ compared to healthy controls $1.62 \mathrm{mg} / \mathrm{L}(P<0.001)$. The two other groups (ISVR and BTM) showed lower CRP concentrations compared to RA cases $(P<0.001)$. Lowest hemoglobin levels were found in BTM patients $(100.4 \mathrm{~g} / \mathrm{L})$. The difference between this group and two other, and to healthy controls shoes significance of $P<0.005$. Based on frequent blood transfusions, serum iron, TIBC and ferritin levels were higher 
in BTM patients - $55.8 \mu \mathrm{mol} / \mathrm{L}, 97.75 \mu \mathrm{mol} / \mathrm{L}$ and $901.22 \mathrm{ng} / \mathrm{mL}$, with significance between other cases and controls of $P<0.001$. Soluble transferrin receptors were found to be the lowest in RA patients (1.26 $\mathrm{mg} / \mathrm{L}$ ), with significance of $P<0.005$. In RA patients we measured IL- 6 by ELISA method and found elevated serum concentrations compared to healthy controls $-3.6 \mathrm{pg} / \mathrm{mL}$ to $1.4 \mathrm{pg} / \mathrm{mL}(P<0.001)$.

We found statistically different results in included groups for serum hepcidin levels. They differ in case if an acute stroke occurs during rheumatoid arthritis and in $\beta$-thalassemia. The results obtained from the serum hepcidin quantification are presented in Figure 1 .

Serum hepcidin levels statistically differ in three ischemic stoke groups: ISVR $87.6 \pm 9.4 \mu \mathrm{g} / \mathrm{L}, \mathrm{RA} 19.4 \pm 0.9 \mu \mathrm{g} / \mathrm{L}$ and BTM $7.9 \pm 1.1 \mu \mathrm{g} / \mathrm{L}$ $(P<0.001)$. In patients with RA and BTM without stroke hepcidin shows serum concentrations from $35.6 \pm 1.4 \mu \mathrm{g} / \mathrm{L}$ and $0.95 \pm 0.3 \mu \mathrm{g} / \mathrm{L}$ $(P<0.001)$. In healthy controls we quantified serum hepcidin as $22.7 \pm 5.1 \mu \mathrm{g} / \mathrm{L}$

In case of acute stroke in RA patients serum hepcidin decreases, reaching reference ranges levels - from $35.6 \mu \mathrm{g} / \mathrm{L}$ to $19.4 \mu \mathrm{g} / \mathrm{L}$ $(P<0.01)$. In the opposites, in BTM patients we found that hepcidin concentration increases in presence of acute stroke - from $0.95 \mu \mathrm{g} / \mathrm{L}$ to $7.9 \mu \mathrm{g} / \mathrm{L}(P<0.005)$.

We found a significant correlation between serum iron levels and hepcidin concentration in included groups: patients with ISVR $(\mathrm{r}=0.620, P<0.001)$, RA patients $(\mathrm{r}=-0.757, P<0.005)$, BTM cases $(\mathrm{r}=-$ $0.865, P<0.001)$, and in control group $(\mathrm{r}=0.423, P<0.001)$. CRP levels correlated to hepcidin concentration in ISVR $(\mathrm{r}=0.689, P<0.005)$, RA $(\mathrm{r}=0.874, P<0.005)$, BTM $(\mathrm{r}=0.589, P<0.01)$, and healthy controls $(\mathrm{r}=0.387, P<0.01)$. IL-6 correlation to hepcidin in serum in RA patients shows significance of $\mathrm{r}=0.765, P<0.001$. Ferritin levels correlated to quantified serum hepcidin in ISVR $(\mathrm{r}=0.578, P<0.005)$, RA ( $\mathrm{r}=0.618, P<0.005), \mathrm{BTM}(\mathrm{r}=0.899, P<0.001)$, and control group $(\mathrm{r}=0.571, P<0.01)$.

\section{Discussion}

Patients with inflammatory and reduced hepcidin are expected to have an iron deficiency. In contrast, those with high level of hepcidin are diagnosed with $\mathrm{ACD}$

Using serum hepcidin levels would help in assessing the need for the application of preparations containing iron. The results suggest that patients with IDA may be subjected to treatment with such drugs, while patients with ACD do not need them.

Rheumatoid arthritis is a multifactorial condition that is associated with ACD [13]. It may also include iron deficiency due to bleeding in the gastrointestinal tract caused by applied therapy; distribution in synovial tissue. Establishment of iron deficiency in populations with ACD is clinically relevant because: 1 ) iron-deficiency anemia (IDA) is treatable, 2) diagnosis can precede further investigation of the cause of anemia, and 3) can prevent unnecessary supplementation with iron. Data from our study indicated a significant increase in serum hepcidin in RA and ACD compared with the control group.

On the other hand cases of acute stroke in thalassemia patients might seriously mask the anemia picture and clinicians might make an incorrect therapeutic choice [14].
Established changes of serum hepcidin in cases of acute stroke might lead to different evaluation of anemia in rheumatoid arthritis patients. Lower hepcidin levels in one patient with rheumatoid arthritis and thalassemia is probably due to the main hereditary disease. There was no acute stroke evidence in this case.

Future of hepcidin is related to the possibility hepcidin antagonists and agonists can be used as a therapeutic agent in the treatment of anemia in inflammation and iron-deficiency anemia. Reducing of hepcidin levels or counteracting the biological effects of hepcidin may lead to a reduction in inflammation on erythropoiesis by mobilization of stored iron and increases intestinal absorption of the element. These new therapeutic approaches could reduce or eliminate all toxic effects of treatment with parenteral iron and Co-reduction needs erythropoietin stimulating agents (ESAs). In these cases, serum hepcidin is suitable therapeutic target in the management of therapy in CKD.

On the other hand the burden of iron overload in thalassemia- $\beta$ were unaffected by treatment with chelators, which can have severe side effects. There are a few studies about micro-hepcidin as an alternative of chelation therapy, especially in patients without transfusion therapy [15]. Treatment with hepcidin may have a beneficial effect and ineffective erythropoiesis.

\section{Conclusion}

Determination of serum hepcidin is still a novelty in Bulgarian medical practice. The introduction of a reliable routine method for the study of hepcidin in biological fluids is a step forward in the treatment of diseases with impaired iron homeostasis. Our study in patients with rheumatoid arthritis and different anemia plus additional acute stroke cases confirms the ability of verified immunochemical method to differentiate the increase and decrease in serum hepcidin in patients with RA. It provides a basis for choosing the correct therapeutic approach in the treatment of anemia.

Our results indicate that serum hepcidin plays an important role for iron overload in cerebral ischemia.

\section{Acknowledgment}

This project is implemented with the financial support of the Medical University - Sofia, as part of Grants - Project 5070/2016, Contract 22/2016 (Project 504/2016) and Contract 1-C/2015 (Project $4608 / 2015$ ). We also kindly appreciate the support from "Marvena" (a "Siemens Healthcare Diagnostics" distributor in Bulgaria), especially to Mrs. Silviya Kirova and Mr. Velizar Dragoev.

\section{References}

1. Weiss G, Goodnough LT. Anemia of chronic disease. N Engl J Med. 2005: 352: 1011-1023.

2. Kemna EH, Tjalsma H, Willems HL, Swinkels DW. Hepcidin: from discovery to differential diagnosis. Haematologica. 2008; 93: 90-97.

3. Goodnough LT, Nemeth E, Ganz T. Detection, evaluation, and management of iron-restricted erythropoiesis. Blood. 2010; 116: 4754-4761.

4. Sullivan JL. Macrophage iron, hepcidin, and atherosclerotic plaque stability. Exp Biol Med (Maywood). 2007; 232: 1014-1020.

5. Valenti L, Swinkels DW, Burdick L, Tjalsma H, Bertelli C, Fatta C, et al Serum ferritin and hepcidin levels predict vascular damage in patients with nonalcoholic fatty liver disease. Am J Hematol. 2009; 84: E236-E375. 
6. Aki HS, Fujita M, Yamashita S, Fujimoto K, Kumagai K, Tsuruta R, et al Elevation of jugular venous superoxide anion radical is associated with early inflammation, oxidative stress, and endothelial injury in forebrain ischemiareperfusion rats. Brain Res. 2009; 1292: 180-190.

7. Tacchini L, Gammella E, De Ponti C, Recalcati S, Cairo G. Role of HIF-1 and NF-kB Transcription Factors in the Modulation of Transferrin Receptor by Inflammatory and Anti-inflammatory Signals. J Biol Chem. 2008; 283: 2067420686 .

8. Amantea D, Bagetta G, Tassorelli C, Mercuri NB, Corasaniti MT. Identification of distinct cellular pools of interleukin-1beta during the evolution of the neuroinflammatory response induced by transient middle cerebral artery occlusion in the brain of rat. Brain Res. 2010; 1313: 259-269.

9. Jia J, Hu YS, Wu Y, Liu G, Yu HX, Zheng QP, et al. Pre-ischemic treadmil training affects glutamate and gamma aminobutyric acid levels in the striata dialysate of a rat model of cerebral ischemia. Life Sci. 2009; 84: 505-511.

10. Viatte L, Lesbordes-Brion JC, Lou DQ, Bennoun M, Nicolas G, Kahn A, et al. Deregulation of proteins involved in iron metabolism in hepcidin-deficient mice. Blood. 2005; 105: 4861-4864.
11. Nicolas G, Chauvet C, Viatte L, Danan JL, Bigard X, Devaux I, et al. The gene encoding the iron regulatory peptide hepcidin is regulated by anemia, hypoxia, and inflammation. J Clin Invest. 2002; 110: 1037-1044.

12. Manolov VE, Atanasova BD, Velizarova MG, Vasilev VG, Tzatchev KN Serum hepcidin levels in Bulgarian population. Clin Lab. 2014; 60: $2001-$ 2006.

13. Manolov V, Yonova D, Vazelov E, Atanasova B, Velizarova M, Vasilev V, et al. Anemia in chronic dialysis patients - the right therapeutic choice? 2014; 2: $270-273$

14. Petrova J, Manolov V, Dimitrov G, Tarnovska-Kadreva R, Yaneva-Sirakova $T$, Velizarova $M$, et al. Serum hepcidin levels and stroke in thalassemia patients. Int J Stroke. 2016; 11: NP50-NP51.

15. Preza GC, Ruchala P, Pinon R, Ramos E, Qiao B, Peralta MA, et al. Min hepcidins are rationally designed small peptides that mimic hepcidin activity in mice and may be useful for the treatment of iron overload. J Clin Invest. 2011; 121: 4880-4888.
Austin J Cerebrovasc Dis \& Stroke - Volume 4 Issue 2 - 2017 ISSN : 2381-9103 | www.austinpublishing group.com

Manolov et al. (C) All rights are reserved
Citation: Manolov V, Petrova J, Hadjidekova S, Petrova M, Traykov L, Tarnovska-Kadreva R, et al. Serum Hepcidin Quantification in Stroke in $\beta$-Thalassemia and Rheumatoid Arthritis Patients. Austin J Cerebrovasc Dis \& Stroke. 2017; 4(2): 1056. 